\title{
NOTICE OF SOME NEW REPTILES FROM THE UPPER TRIAS OF WYOMING.
}

The University of Chicago paleontological expedition to Wyoming the past summer was fortunate in securing a valuable collection of stegocephalian and reptilian remains from the Trias, a part of which is described in the present paper.

The beds whence the fossils were obtained, from forty to eighty feet in thickness, are about two hundred feet below the top of the red-beds and about six hundred feet above their base. Their description will be given in a later paper by Mr. N. H. Brown, their discoverer, and the writer. Meanwhile the horizon may be distinguished by the name Popo Agie ${ }^{\mathrm{I}}$ beds, as suggested by Mr. Brown, from the Popo Agie River, along whose branches they are most characteristically shown.

\section{Dolichobrachium gracile, gen. et sp. nov.}

Coraco-scapula (Fig. I).-Scapula elongate, flattened, directed backward nearly parallel with the long axis of the body; the blade elongate, moderately thickened, and of nearly equal width throughout; back of the middle of the lower margin, there is a slight angular projection. Anteriorly the bone curves sharply downward to the glenoid fossa, at right angles to the shaft, and has a free, thin, rounded margin in front. The upper margin of the glenoid fossa is thick, prominent, and rounded, supported by a strong thickening of the bone above it; in front this thickening has a heavy, rounded margin standing out prominently from the thinned anterior plate of the scapula. The fossa has no rim in front, the surface blending into the non-articular sloping surface extending to the thin front margin of the bone. Nor is there a rim behind, but below the border is very prominent, more so than the upper border, though thinner, the bone being excavated below it to form an obliquely projecting rim. Coracoid elongate antero-posteriorly, the anterior part directed strongly inward; the posterior margin nearly on the same plane as the glenoid fossa and

I Pronounced popo azhie, or, in the vernacular, popózhie. 
the inferior border of the shaft of the scapula. - The anterior part of the coracoid, though preserved, has not yet been fitted to the remainder of the bone; it is rather thick, and scems to have been directed strongly inward. No traces of a supracoracoid foramen, nor of any connecting sutures are visible in the united bones.

Humerus (Fig. 2).-The left humerus, found associated with its corresponding coraco-scapula, is a remarkable bone. The head is thickened, the shaft curved forward and compressed, the condyles have a long articular sweep and are obliquely placed. The dorsal surface proximally is conrex from side to side below the slightly prominent head, the lateral or deltoid process forming a long, backwardly curved margin. On the palmar side the surface is concave, and the head is more prominent, the slightly convex articular surface looking mesad and ventrad.

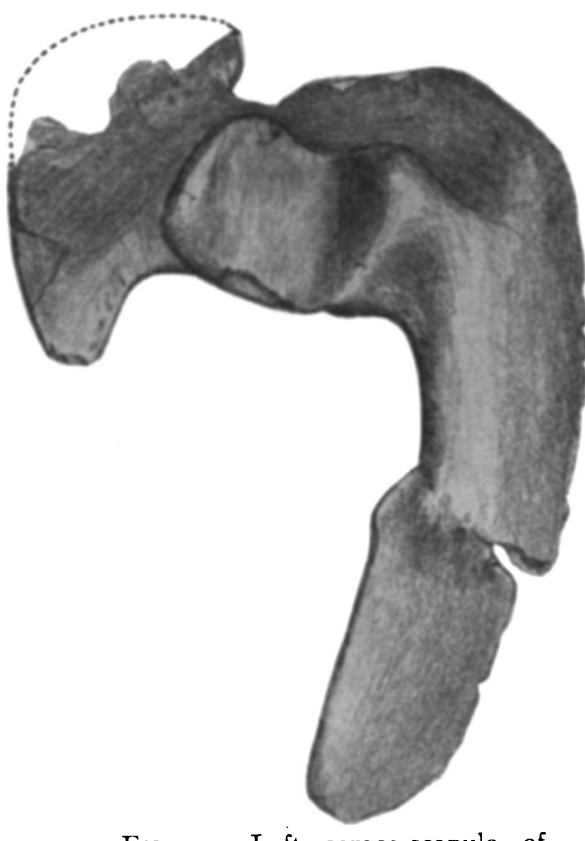

FIg. I.-Left coraco-scapula of Dolichobrachium gracile.

The shaft, distad to the lower end of the deltoid process, is strongly compressed from side to side, with a considerable convexity in front. The condyles stand far backward, the inner one more prominent and slightly longer than the outer one. They are also obliquely placed, so that, when resting on a plane, the plane of the upper part is not more than thirty degrees from the vertical.

The external condyle extends through nearly three-fourths of a circle; the trochlear groove is deep and narrow. On the outer side, a little above the end, there is a thickened, rounded projection, partially scparated from the shaft by a groove; it perhaps corresponds to the supinator ridge. The bone has no internal cavity. 
In addition to the bones described above, the specimen as collected comprises a number of ventral ribs and a large part, perhaps the larger part, of the skull. The latter, however, is badly shattered

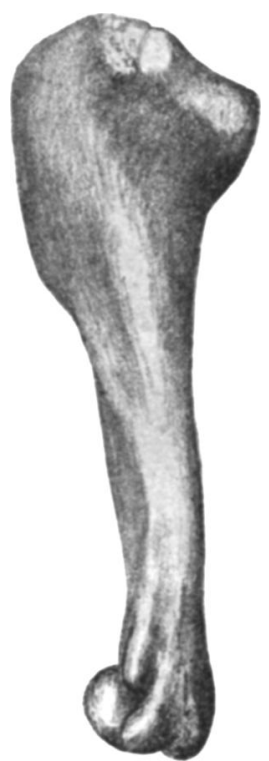

Fig. 2. - Left humerus of Dolichobrachium gracile. from exposure, and will require much patient labor to restore it. In much probability other bones of the skeleton remain to be excavated, and it is hoped to secure them the coming summer.

The specimen was discovered by Mr. Roy Moodie and Mr. E. E. Ball.

What the relations of this animal are it is at present impossible to say, other than it probably belongs to the early rhynchocephaloid type, or in the super-order Diaptosauria of Osborn. I can find nothing in the literature, of either the Permian or Triassic reptiles of Europe or America, which approaches it. The structure of the girdle, the shape of the humerus, and its mode of articulation indicate a swift-moving crawling reptile of considerable size. The skull will doubtless throw much light on the affinities and habits of the animal. I hope to present a discussion of this part of the skeleton within a few months.

\begin{tabular}{|c|c|c|c|c|c|c|}
\hline Height of glenoid fossa & - & - & & - & & $\mathrm{I} 2 \mathrm{O}^{\mathrm{mn}}$ \\
\hline Antero-posterior extent of sa & me & - & - & - & - & IO2 \\
\hline Width of coracoid below rin & of glenoic & id fos & & - & - & 120 \\
\hline Width of scapula above rim & of glenoid & & - & - & - & 152 \\
\hline Antero-posterior expanse of & scapula & - & - & - & - & 460 \\
\hline Width of blade of scapula & - & - & - & - & - & 108 \\
\hline Length of humerus - & - & - & 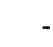 & - & - & 445 \\
\hline Greatest width, upper end & - & - & - & - & - & I47 \\
\hline Width of shaft, lower third & - & - & & & & 44 \\
\hline
\end{tabular}

Eubrachiosaurus browni, gen. et sp. nov.

Left humerus (Fig. 3).-Head, when seen from above, elongate oval or semilunate, the posterior border strongly convex. Tuberosity (median process of Fürbringer, teretial process of Owen) separated by a narrow and constricted depression from the capitular 
border; expanded below, the gently convex surface looking ventrad and mesad, extending a little less than a third of the length of the bone. Below this process, on the inner border, there is a small convexity, which may, perhaps, represent the tricipital process. Inner ventral surface above deeply concave; bounded above and on the side by the margin of the capitular projection and that of the median process. Lateral (deltopectoral) crest elongate and thickened, very protuberant, extending a little more than one-half the length of the bone (ten inches), directed obliquely outward and ventrad; outer margin convex, but produced into an obtuse angle below, the thickness somewhat greater below. In the specimen this process has been slightly crushed dorsad. Posterior surface proximally gently convex, concave on the outer side, with the rounded head strongly protuberant. Shaft below lateral crest

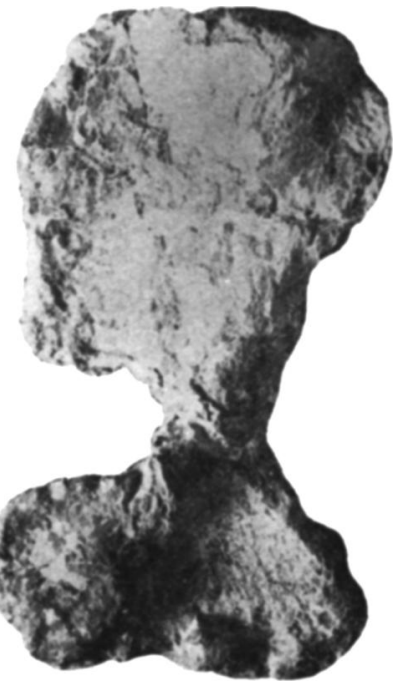

Fig. 3.-Left humerus of Eubrachiosaurus browni. much constricted, its conjugate diameters being nearly equal. Entepicondylar canal directed nearly downward, the flattened bridge over it being the continuation of the lower margin of the lateral crest. Entepicondyle thickened and roughened for muscular attachment; ectepicondylar or supinator ridge broad, arising as high up as the upper margin of the external opening of the epicondylar canal, and nearly as high as the lower end of the lateral crest, its border nearly semicircular in outline, gently curved forward. Olecranal fossa large, shallow, triangular, nearly flat. Radial articular capitular surface large, convex, forming a small, rounded process on the dorsal side and a large one on the ventral side. Ulnar articular surface smaller, but extending nearly as far ventrad, the intervening trochlear groove rather deep and narrow.

Scapula.-An elongate bone, presenting the essential characteristics of a dicynodont scapula, was found lying with its distal end impressed upon the inner side of the ilium, and close by the humerus 
above described. Its size and slenderness seem disproportionate to the massiveness of the humerus, but that it belongs with the pelvis and humerus there can be scarcely a shadow of doubt. It has a thickened articular end below, a part of which is missing - that which protruded from the face of the cliff and led to the discovery of the

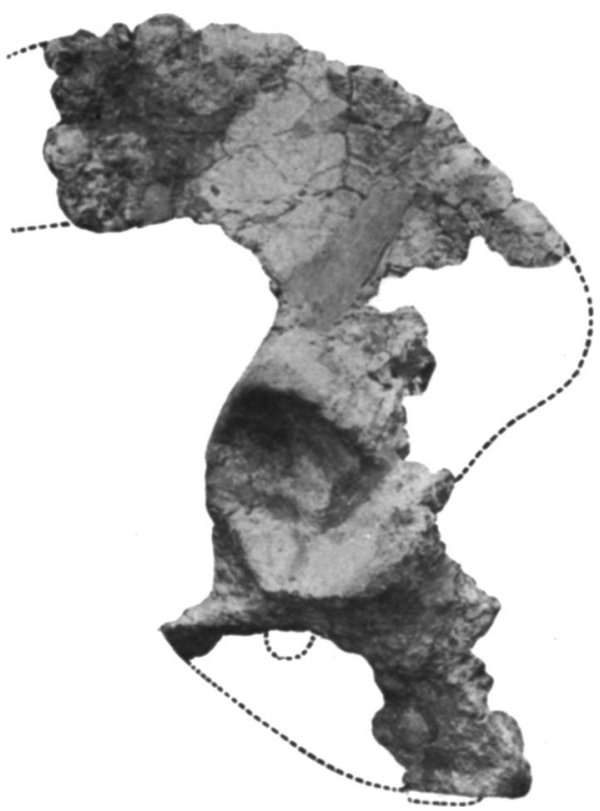

Fig. 4.- Left innominate bone of Eubrachiosaurus broueni. specimen. Doubtless there was another facet here for the coracoid. The upper part is expanded and flattened, with the anterior border thickened, the inner surface somewhat concave. This thickened anterior part is continued into an elevated ridge on the dorsal side, which ends rather abruptly near the lower extremity - the acromion.

Pelvis (Fig. 4).-The bones which, because of their shape, must belong to the left side of the pelvis, from the position in which they were found and from certain peculiarities of their shape, were first thought to belong with the pectoral girdle, and it was not until the specimen had been nearly completely reconstructed that its real nature was apparent. The most remarkably dilated and elongated anterior part of the ilium, had it not been so strongly curved, would rather represent the blade of the scapula, and no articular surfaces for the attachment of the sacral ribs have been detected-there are certainly none such low down on the bone.

The united ischium and pubis were slightly separated from the ilium on the left side, and entirely so on the right side. The connecting surfaces were so incrusted with the tenaciously adhering matrix that their sutural nature is not apparent, though without doubt the separation took place at the suture, since the united ischium and pubis of the opposite side have the same shape. 
The ilium extends upward and forward in a broad curve. The upper portion is broad, flat, and rather thin. The distal part had been broken off before fossilization, and the attaching fracture so corroded and incrusted with matrix, removable with difficulty from the thin bone, that its precise relations are somewhat doubtful. This portion has been omitted in the photograph, but the free, thin, concave border seems to continue the curve before it for about eight inches, the distal portion being somewhat dilated and very thin. Such a shape is most extraordinary for an ilium. This part of the ilium turns outward as though for the protection of the abdominal walls. The posterior border of the ilium was unfortunately lost before the presence of the bone was suspected, lying as it did below the scapula. It was evidently thin.

The acetabulum forms a deep oval cavity, somewhat notched at the upper posterior part. The pubis was directed obliquely inward, and has a strong, everted, articular face, perhaps for an epipubis or prepubis, very much as has been figured in species of dicynodonts. ${ }^{\mathrm{I}}$ A little in front of the middle, and about two inches below the rim of the acetabulum, there is seen a short, free margin, evidently the upper margin of the thyroid (obturator) foramen, and in all probability situated in the line of the suture between the pubis and ischium, since both bones were broken apart in this same place. The border connecting the pubic and ischiadic angles has not yet been reconstructed, but patient labor will doubtless fit in the whole of this portion from the many thin fragments preserved in each of the specimens.

The pubis and ischium are turned inward toward the median line.

Lying upon the distal part of the humerus there was a small bone, about six inches in length, which seems to be a sacral rib, resembling as it does the corresponding bones of some dinosaurs.

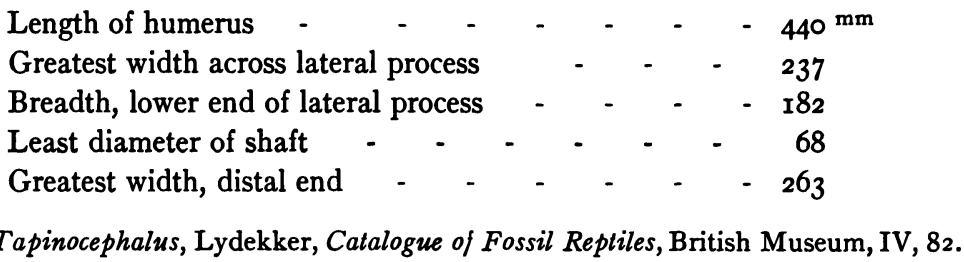




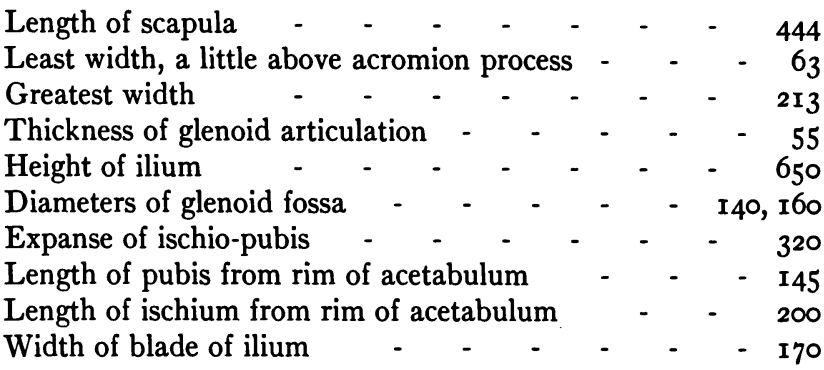

The specimen above described was found protruding from a face of the cliff near the uppermost part of the Popo Agie beds, in the vicinity of the Little Popo Agie River, by Mr. Roy Moodie and the writer. The specimen was partly worked out by myself, and later by Mr. Branson and Mr. Moodie. The great difficulties under which the specimen was secured prevented at the time exploration for other bones. There can be little doubt but that other parts of the skeleton, perhaps the larger portion, still remain in the rocks, and, it is hoped, will be secured another season.

What the relations of Eubrachiosaurus are with other reptiles it is yet impossible to say with much degree of certainty. I do not believe that the genus belongs with the Pareiasauria, chiefly because of the presence of an entepicondylar foramen, though the humerus resembles that of Pareiasaurus somewhat. The humerus recalls that of Platypodosaurus, but, upon the whole, I believe that the animal will be found to be nearest related to Tapinocephalus or Phocosaurus, from the Karoo beds of South Africa. The ilium is incompletely known in these genera, but the size of the acetabulum, the shape and structure of the ischio-pubis, the posterior projection of the ilium and the limited sacral attachment, all point to that genus. At all events, I believe that the genus, as also Placerias Lucas, and the following, belong among the true Anomodontia. From Placerias Lucas, ${ }^{\mathbf{I}}$ from the Trias of Arizona, this form differs very evidently in the great expansion of the lower end, the ectepicondyle, which is figured in Placerias as convex and thick, being widely expanded.

Brachybrachium brevipes, gen. et sp. nov.

A single humerus, though incomplete, found near the upper part of the Popo Agie beds, and in almost identically the same horizon as

s Proceedings of the U.S. National Museum, 1904, p. 194. 
that of the preceding genus, shows such decided differences, and, moreover, is so characteristic, that I venture to describe and name it. The upper extremity is thin and narrow; probably some portion of this had been lost prior to fossilization, but inasmuch as Broom describes this extremity in Udenodon as narrow, I believe that little is missing. The thick and massive lateral process is directed upward. The inner condyle is rounded below, showing that nearly the whole length of the bone is present, though the outer condyle, that projecting from the face of the cliff, is wanting. The large entepicondylar canal begins considerably above the lower angle of the lateral process, and not wholly below the process, as in Eubrachiosaurus. The bridge covering it is very stout. The median process is small, not protuberant and flattened, as in the last genus. The outer border is concave from above downward, strongly convex transversely. At the lower end of the part preserved the

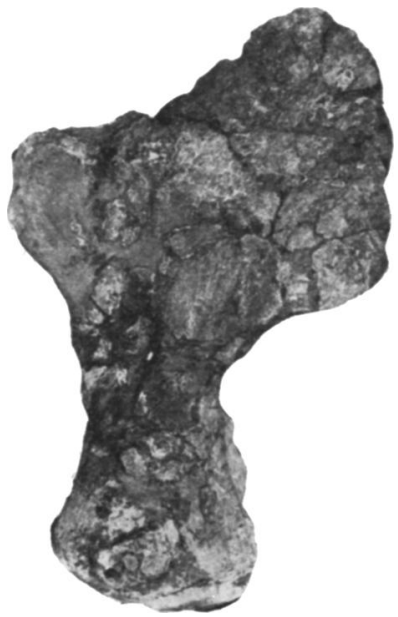

Fig. 5.- Left humerus of Brachybrachium brevipes. border becomes thinner, but it is not possible that there was any such supinator expansion as is shown in Eubrachiosaurus; if any, it was situated much more distad. The condyles must have been remarkably broad, equal to much more than half the length of the bone, and the olecranal fossa is large and deep. The upper part of the palmar surface of the ulnar process is preserved, and is much more massive and prominent than in Eubrachiosaurus. If the radial prominence was relatively as large, it must have been very massive.

The specimen was discovered by Mr. Roy Moodie, and removed from the very hard sandstone by him and the writer.

$\begin{array}{llllll}\text { Length of the bone as preserved } & - & - & - & - & 255^{\mathrm{mm}} \\ \text { Width across lateral process } & - & - & - & - & \mathrm{I} 97 \\ \text { Estimated width of condyles } & - & - & - & - & 200 \\ \text { Least diameter of shaft in plane of condyles } & - & - & 70\end{array}$




\section{Paleorhinus bransoni, gen. et sp. nov.}

(Fig. 6).-A new genus of phytosaurs, somewhat more primitive than any hitherto made known, though agreeing rather better with Belodon than Phytosaurus, is represented in the collection by a nearly perfect skull in excellent condition. The genus is especially characterized by the more anterior position of the external nares, their nonseparation by the nasal bones, and by the more lateral position of the orbits. The accompanying outline figure of the side of the specimen will show the positions of the various openings better than they can be described. Some of the sutures have not yet been determined. The external nares are at the extremity of a nose-like protuberance, the openings looking partly upward, partly forward

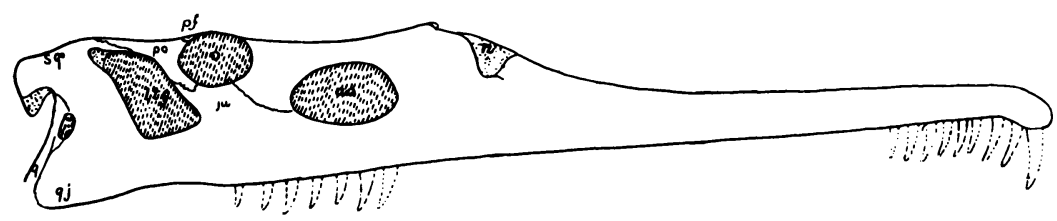

Fig. 6.-Skull of Paleorhinus bransoni.

and outward, separated by two, thin, vertical plates, perhaps the mesethmoids. The ontorbital opening is elongate oval in shape, and situated between the orbits and nares. The anterior part of the beak is turned downward, as in Phytosaurus, and has a single large tooth on each side. The posterior end of the mandible is shaped much as it is figured in Mystriosuchus by Fraas, that is with a very small angular projection situated low down. The front end of the mandible is missing.

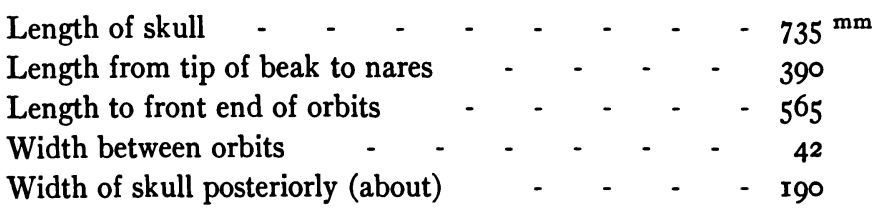

From Typothorax Cope and Episcoposaurus Cope, based upon fragments, the form is evidently different. From Heterodontosuchus Lucas, from the Trias of Utah, based upon the anterior end of the mandible, I cannot state the differences with assurance. The only available character given for that genus is the proximity of the 
teeth, since all the teeth had fallen from the sockets in this specimen. The teeth are not separated by an extremely thin partition, but have quite an interval between them, in some cases equal to the diameter of the sockets. I feel more confidence in the distinction, however, from the fact that another genus in the collection has the teeth much more closely placed.

Another form, represented by a complete skull of larger size, in the collection, has the anterior nares apparently placed much further forward than in the present genus, or at least the beginning of the slender beak is much further forward. Yet another skull, of large size and nearly complete, has been nearly freed from its matrix. It measures $960 \mathrm{~mm}$ in length; the nares are not as far forward as is the front end of the ontorbital opening, though more anteriorly placed than in B. scolopax Cope, and the strongly deflected anterior end of the beak has three large teeth on each side. The hind teeth are flattened and serrate. Still another skull seems different from any of the forcgoing.

S. W. Williston. 